Check for updates

Cite this: RSC Adv., 2018, 8, 11006

Received 5th January 2018

Accepted 2nd March 2018

DOI: $10.1039 / c 8 \mathrm{ra00118a}$

rsc.li/rsc-advances

\title{
Up-conversion white emission and other luminescence properties of a $\mathrm{YAG}: \mathrm{Yb}_{2} \mathrm{O}_{3} \cdot \mathrm{Tm}_{2} \mathrm{O}_{3} \cdot \mathrm{Ho}_{2} \mathrm{O}_{3} \mathrm{aSiO}_{2}$ glass- nanocomposite $\uparrow$
}

\author{
Andrzej M. Kłonkowski, (D) *a Benedykt Kukliński, ${ }^{b}$ Mariusz Kubus, ${ }^{c}$ Jacek Ryl, ${ }^{d}$ \\ Karol Szczodrowski, (D) ${ }^{b}$ Dorota Wileńska ${ }^{a}$ and $H_{\text {. }}$-Jürgen Meyer (D) ${ }^{c}$
}

\begin{abstract}
We report on a glass-nanocomposite material consisting of yttrium aluminum garnet $\left(\mathrm{Y}_{3} \mathrm{Al}_{5} \mathrm{O}_{12}, \mathrm{YAG}\right)$ nanocrystals co-doped with $\mathrm{Yb}^{3+}, \mathrm{Tm}^{3+}$ and $\mathrm{Ho}^{3+}$ ions as well as entrapped into a $\mathrm{SiO}_{2}$ xerogel. This 94YAG $5 \mathrm{Yb}_{2} \mathrm{O}_{3} \cdot 0.8 \mathrm{Tm}_{2} \mathrm{O}_{3} \cdot 0.2 \mathrm{Ho}_{2} \mathrm{O}_{3} \mathrm{CSiO}_{2}$ (abbr. $\mathrm{YAG}: \mathrm{YbTmHo}\left(\mathrm{SSiO}_{2}\right)$ nanocomposite material has been prepared by sol-gel procedure. Its structure and morphology has been characterized by means of $X$-ray diffraction (XRD) and scanning electron microscope (SEM) techniques as well as energy dispersive $X$-ray (EDX), X-ray photoelectron (XPS) and luminescence spectroscopies. The luminescent glassnanocomposite exhibited an up-conversion effect under $\lambda_{\text {exc }}=980 \mathrm{~nm}$ and emission when excited under $355 \mathrm{~nm}$ in steady-state conditions. Then time-resolved luminescence emission was observed, when the sample was excited at 290 and $355 \mathrm{~nm}$ by a pulse laser. Average decay times for the $\mathrm{SiO}_{2}$ matrix and for some transitions of the $\mathrm{Tm}^{3+}$ and $\mathrm{Ho}^{3+}$ dopants present in the YAG:YbTmHo@SiO 2 material have been evaluated. The luminescent nanocomposite when excited under 290 or $355 \mathrm{~nm}$ wavelengths in both conditions emits blue light. However, the nanocomposite is promising as a singlesource white-light phosphor owing to its up-conversion luminescence under $980 \mathrm{~nm}$ excitation. Such optical features make the studied material an alternative phosphor.
\end{abstract}

\section{Introduction}

Up-conversion is an anti-Stokes process in which a near infrared photon is converted into visible or even ultraviolet light owing to multi-photon action. Among various near infrared excitation lasers, the $980 \mathrm{~nm}$ one is the most commonly used excitation source generating up-conversion emission. ${ }^{1}$ Actually there are many up-conversion processes with widely different conversion efficiencies. The processes require energy levels which are resonant with the incoming or outgoing radiation. Lanthani$\operatorname{de}(\mathrm{III})$ ions $\left(\mathrm{Ln}^{3+}\right)$ are very suitable as the emitting centers owing to their numerous electronic levels and narrow emission bands. Among the $\mathrm{Ln}$ (III) ions $\mathrm{Ho}^{3+}$ can be applied to obtain red and green up-conversion luminescence and $\mathrm{Tm}^{3+}$ acts as a blue

${ }^{a}$ Faculty of Chemistry, University of Gdańsk, Wita Stwosza, 80-308 Gdańsk, Poland. E-mail: andrzej.klonkowski@ug.edu.pl

${ }^{b}$ Institute of Experimental Physics, University of Gdańsk, Wita Stwosza, 80-308 Gdańsk, Poland

'Institute of Inorganic Chemistry, University of Tuebingen, Auf der Morgenstelle 18, 72076 Tuebingen, Germany

${ }^{d}$ Chemical Faculty, Gdańsk University of Technology, G. Narutowicza 11/12, 80-233 Gdańsk, Poland

$\dagger$ Electronic supplementary information (ESI) available. See DOI: 10.1039/c8ra00118a emitting activator under infrared (980 $\mathrm{nm}$ ) excitation. While, $\mathrm{Yb}^{3+}$ can act as the sensitizer enhancing the emission efficiency due to appropriate structure of energy levels and longer decay lifetime of the excited states. ${ }^{2}$

The efficiency of the system depends strongly on the choice of the host matrix. It is known that oxides are less suitable than fluorides, since lifetimes in the former are shorter than in the latter due to stronger interaction between the luminescent ion and its coordination environment. Since in the up-conversion oxide material co-doped, e.g. with $\mathrm{Yb}^{3+}$ and $\mathrm{Er}^{3+}$ the lifetime of the intermediary ${ }^{4} \mathrm{I}_{11 / 2}\left(\mathrm{Er}^{3+}\right)$ is shorter, in consequence the total efficiency of the up-conversion process will be lower, in contrast to fluoride material. ${ }^{3}$ Irrespective of this fact there are many papers devoted to up-conversion in oxide materials, among them also works considering yttrium aluminum garnet (e.g. ref. 2 and 4-11).

Yttrium aluminum garnet (YAG) is a prominent crystalline material of the garnet group. The choice of YAG relies on this material exhibiting exceptional optical transparency, having a cubic crystallographic structure that can well accommodate such dopants as lanthanide ions. ${ }^{12,13}$ YAG nanocrystals doped with $\mathrm{Ln}^{3+}$ ions were prepared using many different methods. ${ }^{7,14,15}$

A nanocomposite is defined as a material consisting of at least two different solid phases. In our case glassy silica as the 
host phase of larger extent plays a matrix role. Then the nanosized YAG guest phase doped with Ln(III) ions is dispersed into the matrix. Obviously, the constituent phases of the composite are separated by distinct interface. In the nanocomposites, the guest nanoparticles have dimension in the range 1-100 $\mathrm{nm}$. In this type of nanocomposite materials glass is an excellent host owing to its several inherent superior properties compared to those of other encapsulating hosts. There are many types of glass-nanocomposites depending on the compositions, sizes and shapes of the nano-guests as well as processing parameters. ${ }^{16}$

One of the encapsulating methods used in nanocomposite preparation is sol-gel processing. This method involves the generation of colloidal suspensions (sols) which are subsequently converted to viscous gels and then to rigid xerogels. ${ }^{17}$ Thus, by sol-gel procedure crystalline particles can be immobilized in a solid xerogel. Wide range of inorganic and hybrid organic-inorganic composite materials share this common preparation procedure. In contrast to bulk materials prepared by the melting method, sol-gel materials can be obtained as thin films and coatings. If these materials are transparent, then they gain a competitive advantage with respect to bulk glasses and crystals. It is important especially in glass-nanocomposite luminescent materials doped with such luminescent species as $\mathrm{Ln}^{3+}$ ions, where the nanosize of the $\mathrm{Ln}^{3+}$ doped crystals is crucial to avoid light scattering. The nanocrystals play important role, when activated by lanthanide ions. The presence of the crystalline environment around the lanthanide ion allows high absorption and emission cross sections as well as tailoring of the ion-ion interaction by the control of the lanthanide ion partition. This last point is crucial and still an object of intense experimental and theoretical studies.

The integration of luminescent nanocrystals into vitreous matrix can lead to new optical nanocomposites. There is growing interest to integrate up-conversion nanocrystals with an optical matrix. Not only glasses but also rigid vitreous xerogels can serve as indispensable optical matrix materials owing to their high optical transparency, thermomechanical strength and the ability (especially in the case of xerogels) to be shaped into an almost unlimited range of geometrical structures. ${ }^{18}$ However, it remains a preparation challenge to integrate up-conversion nanoparticles with tailored nanophotonic properties into a vitreous matrix to create a new hybrid optical material. Wet chemistry is the satisfied synthetic technique in the case of up-conversion nanocrystals because it enables control over crystallite phase, size, shape, composition and nanostructure. ${ }^{19-21}$ This control gives a clear advantage over in situ glass ceramic procedure by synthesizing nanocrystals and glass separately, and then integrate them into a hybrid material. This preparation method can overcome the limitations of the glass-ceramic processing. Among the limitations is an extremely high risk of completely dissolving the nanosized crystals at higher temperatures.

Up-conversion nanocrystals containing thousands of $\mathrm{Ln}^{3+}$ ions emit high brightness up-conversion by utilizing highirradiance excitation to enrich the effective emitters ${ }^{\mathbf{1 9 , 2 0 , 2 2}}$ or clustering $\mathrm{Yb}^{3+}$ sensitizers in arrays at sublattice level to promote localized excited states. ${ }^{23}$
In our study glass-nanocomposites consisting of the $\mathrm{Ln}^{3+} \mathrm{co}^{-}$ doped YAG nanocrystals incorporated into glassy silica matrix by sol-gel procedure were synthesized. We demonstrate that this approach allows incorporation of a controlled amount of YAG:Ln up-conversion nanocrystals with well-defined concentrations of $\mathrm{Ln}^{3+}$ ions into amorphous xerogel. The vitreous materials doped with up-conversion nanocrystals exhibit high transparency and identical glassy xerogel structure as a blank silica xerogel. Aim of the study is to compare luminescence of the glass nanocomposite excited in different conditions, viz. in steady-state $\left(\lambda_{\text {exc }}=355\right.$ and $\left.980 \mathrm{~nm}\right)$ or by pulse laser $\left(\lambda_{\text {exc }}=290\right.$ and $355 \mathrm{~nm}$ ) spectroscopy.

\section{Experimental}

\section{Synthetic procedures}

Pure $\mathrm{Y}_{3} \mathrm{Al}_{5} \mathrm{O}_{12}$ (YAG) and co-doped $94 \mathrm{Y}_{3} \mathrm{Al}_{5} \mathrm{O}_{12} \cdot 6 \mathrm{Ln}_{2} \mathrm{O}_{3}$ (in $\mathrm{mol} \%$ ) materials (abbr. YAG:Ln, where $\mathrm{Ln}=\mathrm{Yb}$, Tm and Ho), were synthesized by glycol modification of the sol-gel procedure after Veith et al. ${ }^{\mathbf{2 4}}$ The pure YAG as well as doubly co-doped 94YAG $\cdot 5 \mathrm{Yb}_{2} \mathrm{O}_{3} \cdot 1 \mathrm{Ho}_{2} \mathrm{O}_{3}$ (abbr. YAG:YbHo) and triply co-doped 94YAG $\cdot 5 \mathrm{Yb}_{2} \mathrm{O}_{3} \cdot 0.8 \mathrm{Tm}_{2} \mathrm{O}_{3} \cdot 0.2 \mathrm{Ho}_{2} \mathrm{O}_{3}$ (abbr. YAG:YbTmHo) agglomerated crystals were powdered in an agate mortar and then pulverized in methanol slurry to nanosize particles by an ultrasonic technique for $3 \mathrm{~h} .^{25}$ The chemicals for the doped YAG synthesis such as yttrium trioxide $\left(\mathrm{Y}_{2} \mathrm{O}_{3}\right)$, aluminum nitrate $\left[\mathrm{Al}\left(\mathrm{NO}_{3}\right)_{3} \cdot 5 \mathrm{H}_{2} \mathrm{O}\right]$ and appropriate lanthanide salts $\mathrm{Ln}\left(\mathrm{NO}_{3}\right)_{3} \cdot 5 \mathrm{H}_{2} \mathrm{O}$ (where $\mathrm{Ln}=\mathrm{Yb}$, Tm and $\mathrm{Ho}$ ) of p.a. grade were purchased from Aldrich Co. While acetic acid $\left(\mathrm{CH}_{3} \mathrm{COOH}\right)$, methanol $\left(\mathrm{CH}_{3} \mathrm{OH}\right)$ and 1,2-ethanediol (glycol, $\mathrm{HOCH}_{2} \mathrm{CH}_{2} \mathrm{OH}$ ) of p.a. grade were from Polish Chemical Reagents.

The co-doped YAG:YbHo and YAG:YbTmHo nanopowders were immobilized into silica xerogel by sol-gel processing in a one-pot method. ${ }^{17} 2.5 \mathrm{~cm}^{3}$ of tetramethoxysilane (TMOS was) dissolved in $5 \mathrm{~cm}^{3}$ of methanol and $1 \mathrm{~cm}^{3}$ of water was added. The mixture was stirred and $1.2 \mathrm{~cm}^{3}$ of $\mathrm{NH}_{3}(\mathrm{aq})$ catalyst dropwise was added. After that the $\mathrm{MeOH}$ sol consisting of the co-doped YAG nanoparticles together with the sol-gel mixture was stirred for $15 \mathrm{~min}$. The molar ratio of TMOS : $\mathrm{H}_{2} \mathrm{O}: \mathrm{MeOH}$ was established as $1: 4: 8$. After two days, the co-doped YAG nanocrystals YAG:YbHo@ $\mathrm{SiO}_{2}$ and $\mathrm{YAG:YbTmHo@SiO}$ incorporated into rigid wet gels with the materials were obtained. The nanocomposites were dried at $200{ }^{\circ} \mathrm{C}$, then crushed and sieved $(0.25-0.50 \mathrm{~mm}) .{ }^{25}$ After that they were calcined at $200,600,800$ and $1000{ }^{\circ} \mathrm{C}$ for 3 hours. The chemicals for the silica matrix preparation such as tetramethoxysilane (TMOS) was purchased from Aldrich Co. but methanol $\left(\mathrm{CH}_{3} \mathrm{OH}\right)$ and ammonia $\mathrm{NH}_{3}(\mathrm{aq})$ were from Polish Chemical Reagents.

\section{Apparatus}

The ultrasonic equipment for the crystals crushing to nanoparticles was Sonorex Super RK 103H. After straining and drying at $120{ }^{\circ} \mathrm{C}$ the nanocrystals were thermally treated at $200{ }^{\circ} \mathrm{C}$ in a programmable oven equipped with an SM-946 temperature controller. 
Powder X-ray diffraction (XRD) analysis of the YAG, doped and co-doped YAG:Ln nanocrystals as well as YAG:Ln@SiO nanocomposites was made using a Bruker diffractometer of the D2Phaser model employing $\mathrm{CuK} \alpha$ radiation operated at $30 \mathrm{kV}$ and $0.2 \mathrm{~mA}$. The XRD patterns were collected using scanning steps of $0.02 \mathrm{deg}$. and counting time $0.4 \mathrm{~s}$ per step. The average crystalline size as well as percentage of crystallinity were calculated using Diff. EVA software provided by Bruker.

The topography of the samples was characterized using scanning electron microscope SEM S-3400N (Hitachi, Japan), equipped with a tungsten source. A secondary electron (SE) detector was used and analysis was performed under $20 \mathrm{kV}$ accelerating voltage.

Chemical composition of the investigated materials was examined by means of energy dispersive X-ray spectroscopy (EDX) equipped with ThermoFisher Scientific detector attached to (SEM) and X-ray photoelectron spectroscopy (XPS) fitted with ThermoFisher Scientific: Escalab 250Xi utilizing monochromatic Al-K $\alpha$ source with charge neutralization implemented by means of flood gun. High-resolution XPS spectra were recorded at energy step size of $0.1 \mathrm{eV}$ at pass energy $10 \mathrm{eV}$. In order to normalize the spectroscopic measurements, the $X$ axis (binding energy) from XPS spectrum was calibrated for the peak characteristics for neutral carbon C1s $(284.6 \mathrm{eV}){ }^{26}$ Data analysis was performed using Avantage software provided by the manufacturer.

Photoluminescence spectra were recorded using a monochromators SPM2 produced by Carl Zeiss Jena for excitation and emission. An excitation source in this system was Osram $250 \mathrm{~W}$ ozone-free Xenon lamp and laser produced by Optoelectronics Tech. Co., Ltd MDL-III-980L-1000 mW. Fluorescence intensity was measured using a Hamamatsu R928 Side-on photomultiplier. All spectra were recorded at $300 \mathrm{~K}$.

To follow the luminescence kinetics, we used a system consisting of a YAG:Nd (PL 2143 A/SS) laser and system OPG (optical paramagnetic generators). This system can generate $30 \mathrm{ps}$ laser pulses, with the frequency of $10 \mathrm{~Hz}$ with wavelengths ranging 290 and $355 \mathrm{~nm}$. The emission signal was analyzed by a Bruker Optics 2501S spectrometer and the Hamamatsu Streak Camera model C4334-01 with a final spectral resolution $0.47 \mathrm{~nm}$. Luminescence spectra were collected by integration of the streak camera pictures over time intervals, whereas luminescence decays were obtained by the integration of streak camera images over the wavelength intervals. ${ }^{27}$

\section{Results and discussion}

\section{XRD patterns}

XRD patterns of the pure YAG (curve a), YAG doped with $6 \mathrm{~mol} \%$ $\mathrm{Yb}^{3+}$ (YAG:Yb, curve b) and YAG triply co-doped with $\mathrm{Yb}^{3+}, \mathrm{Tm}^{3+}$ and $\mathrm{Ho}^{3+}$ (YAG:YbTmHo, curve c) dried at $200{ }^{\circ} \mathrm{C}$ are presented in Fig. S1. $\dagger$ All the patterns are consistent with the standard data corresponding to cubic $\mathrm{Y}_{3} \mathrm{Al}_{5} \mathrm{O}_{12}$ nanocrystals (PDF 01-082$3500)$, i.e. no secondary crystalline phase is observed and presence of the dopants did not change the crystalline structure. The calculated by the Scherrer formula average size of the nanocrystals was equal to $27 \pm 4 \mathrm{~nm}$.
XRD patterns of the thermally treated YAG:YbTmHo@SiO nanocomposite is shown in Fig. S2. $\dagger$ The sample was dried at $200{ }^{\circ} \mathrm{C}$ and then calcined at 600,800 and $1000^{\circ} \mathrm{C}$. As previously, the XRD patterns are in accordance with the YAG standard data. The average crystallite sizes of the triply co-doped YAG nanoparticles in the nanocomposite collected in Table S1† are within experimental error close to the crystallite size of the un-doped, doubly and triply co-doped YAG nanoparticles. The crystallinity percentage of the samples were estimated. Its values change a little with temperature of the thermal treatment (see Table S1†).

\section{SEM images}

SEM micrographs of the pure YAG and doped YAG:Yb powder samples presented in Fig. 3S(a and $\mathrm{b}, \uparrow$ respectively) exhibit agglomerated crystals. Then in images of greater enlargement in insets are shown nanoparticles which average size could be estimated to $c a .30 \mathrm{~nm}$. It is within experimental error close to the size calculated by the Scherrer formula (vide supra). On the other hand, SEM image of the YAG:YbTmHo@SiO ${ }_{2}$ nanocomposite powder thermally treated at $600{ }^{\circ} \mathrm{C}$ shows agglomerates (Fig. S4†). Image of greater enlargement in inset shows the sphere-like nanoparticles consisted of the doped YAG nanocrystals capped with amorphous $\mathrm{SiO}_{2}$. Size of the nanoparticles is near two-fold greater than size of the YAG and YAG:Yb nanocrystals.

\section{EDS and XPS measurements}

EDS measurement confirm the composition of the YAG and Ybdoped YAG nanocrystals (Fig. S5, $\dagger$ inset). Whereas highresolution XPS spectra of the YAG and YAG:Yb demonstrated in Fig. $\mathrm{S} 6 \dagger$ allow to calculate the $\mathrm{Y} / \mathrm{Al} / \mathrm{O}$ ratio for both the samples. The results give a close match to $\mathrm{Y}_{3} \mathrm{Al}_{5} \mathrm{O}_{12}(3.0 / 6.4 / 11.6$ and 3.0/6.1/11.9 for YAG and YAG:Yb samples, respectively) proving their high purity (see Table S2 $\dagger$ ).

\section{Luminescence spectroscopy}

Steady-state emission spectra. The normalized upconversion emission spectra recorded at room temperature under near infrared (NIR) excitation at $980 \mathrm{~nm}$ for the co-doped YAG nanocrystals and the glass-nanocomposites with silica are compared in Fig. 1(A and B). In general, the emission spectra of the co-doped YAG:YbHo and YAG:YbTmHo nanocrystals (curves a) did not change after their incorporation into silica xerogel (compare with curves b, i.e. the YAG:YbHo@SiO ${ }_{2}$ and YAG:YbTmHo@SiO ${ }_{2}$ nanocomposite spectra, respectively).

The up-conversion emissions shown in Fig. 1A are generated by two- and three-photon processes such as energy transfer (ET) and excited state absorption (ESA) illustrated in the known schematic energy level diagrams presented in Fig. 2 for $\mathrm{Ho}^{3+}$ ions. In the first step $\mathrm{Yb}^{3+}$ sensitizer is excited under $980 \mathrm{~nm}$ from the ground state ${ }^{2} \mathrm{~F}_{7 / 2}$ to the ${ }^{2} \mathrm{~F}_{5 / 2}$ one. Then, occurs the $\mathrm{Yb}^{3+}:{ }^{2} \mathrm{~F}_{5 / 2} \rightarrow$ $\mathrm{Ho}^{3+}:{ }^{5} \mathrm{I}_{6}$ transfer. In this situation either the non-radiative transition $\mathrm{Ho}^{3+}:{ }^{5} \mathrm{I}_{6} \rightarrow{ }^{5} \mathrm{I}_{7}$ takes place and subsequently by step (2) the $\mathrm{Ho}^{3+}$ is excited to the ${ }^{5} \mathrm{~F}_{5}$ state or directly occurs the $\mathrm{Ho}^{3+}:{ }^{5} \mathrm{I}_{6} \rightarrow$ ${ }^{5} \mathrm{~F}_{4},{ }^{5} \mathrm{~S}_{2}$ transition by two-photon process (step 2) from $\mathrm{Yb}^{3+}$. In 

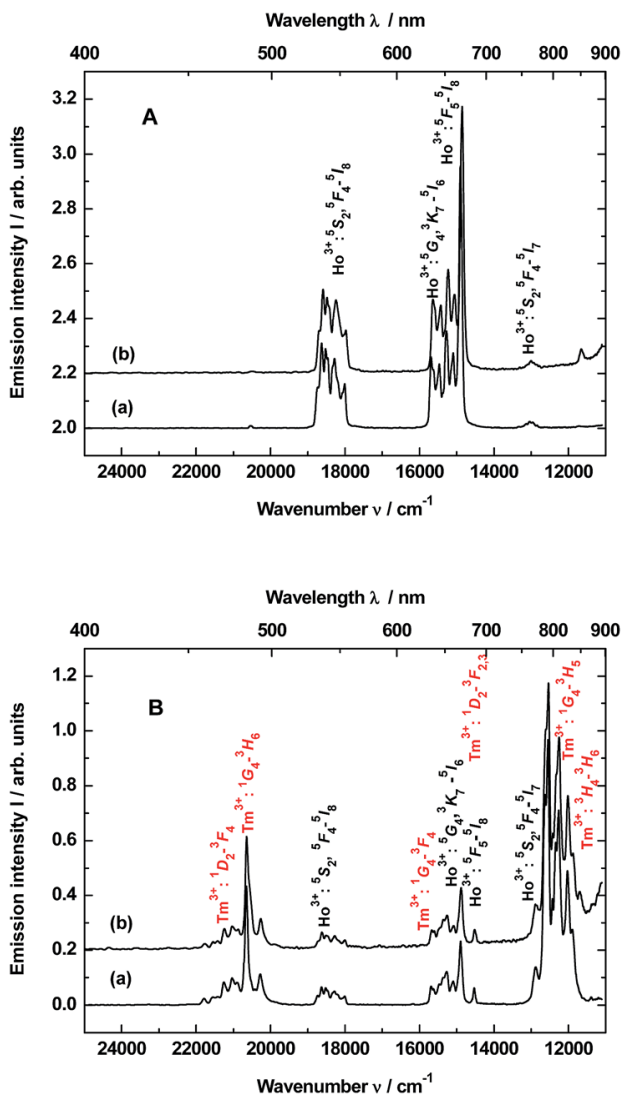

Fig. 1 Up-conversion emission spectra of the samples: (A) YAG:YbHo nanocrystals (curve a) and $\mathrm{YAG}: \mathrm{YbHoOSiO}_{2}$ glass nanocomposite (curve b) as well as (B) YAG:YbTmHo nanocrystals (curve a) and YAG:YbTmHo@SiO ${ }_{2}$ glass nanocomposite (curve b). The samples dried at $200{ }^{\circ} \mathrm{C}$ were excited under $\lambda_{\text {exc }}=980 \mathrm{~nm}$ by the laser in steadystate condition.

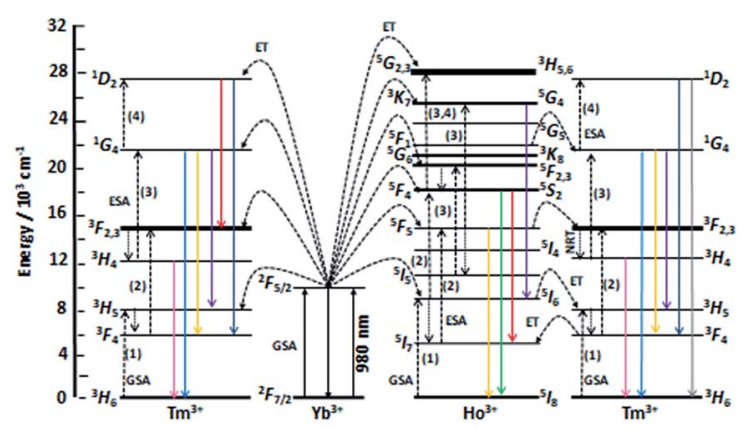

Fig. 2 Scheme of energy levels of $\mathrm{Yb}^{3+}$ (sensitizer) as well as $\mathrm{Tm}^{3+}$ and $\mathrm{Ho}^{3+}$ (activators) in YAG:YbTmHo@SiO 2 nanocomposite. The scheme demonstrates up-conversion mechanisms of the emissions under $980 \mathrm{~nm}$ laser excitation. GSA means ground state absorption, ESA excited state absorption, ET - energy transfer and NRT - non-radiative transition. After ref. 22 and 28.

former case the red emission about $670 \mathrm{~nm}\left(14870 \mathrm{~cm}^{-1}\right)$ corresponds to the ${ }^{5} \mathrm{~F}_{5} \rightarrow{ }^{5} \mathrm{I}_{8}$ transition. Whereas in the latter case can be present two transitions, viz. ${ }^{5} \mathrm{~F}_{4},{ }^{5} \mathrm{~S}_{2} \rightarrow{ }^{5} \mathrm{I}_{8}$ and ${ }^{5} \mathrm{~F}_{4},{ }^{5} \mathrm{~S}_{2} \rightarrow{ }^{5} \mathrm{I}_{7}$. Owing these transitions are observed such emission bands as green one at about $550 \mathrm{~nm}\left(18180 \mathrm{~cm}^{-1}\right)$ and near-infra red (NIR) band centered at $764 \mathrm{~nm}\left(13004 \mathrm{~cm}^{-1}\right)$, respectively. However, after the ${ }^{5} \mathrm{~F}_{5} \rightarrow{ }^{5} \mathrm{I}_{5}$ non-radiative decay three-photon process (step 3) takes place the ${ }^{5} \mathrm{~F}_{5} \rightarrow{ }^{5} \mathrm{G}_{4},{ }^{3} \mathrm{~K}_{7}$ transition. The ${ }^{5} \mathrm{G}_{4},{ }^{3} \mathrm{~K}_{7} \rightarrow{ }^{5} \mathrm{I}_{6}$ relaxation generates an emission band peaked at $\left.c a .650 \mathrm{~nm}\left(15380 \mathrm{~cm}^{-1}\right)\right)^{4,22}$

Emission spectra shown in Fig. 1B are superpositions of spectra consisting of lines assigned to transitions of $\mathrm{Ho}^{3+}$ and $\mathrm{Tm}^{3+}$ dopants in YAG:YbTmHo and its glass nanocomposite counterpart YAG:YbTmHo@SiO ${ }_{2}$. The observed emission bands of $\mathrm{Tm}^{3+}$ are due to two-, three- and four-photon up-conversion processes. As previously, the up-conversion mechanism starts when the excited $\mathrm{Yb}^{3+}$ ion transfers its energy to the $\mathrm{Tm}^{3+}$ and the latter ion reaches the excited ${ }^{3} \mathrm{H}_{5}$ level. As in the case of $\mathrm{Ho}^{3+}$ it is a phonon assisted energy transfer because there is energy difference between the excited state of $\mathrm{Yb}^{3+}$ and the excited ${ }^{3} \mathrm{H}_{5}$ level of $\mathrm{Tm}^{3+}$ (see left part of the energy diagram in Fig. 7). Then after the non-radiative relaxation $\mathrm{Tm}^{3+}:{ }^{3} \mathrm{H}_{5} \rightarrow{ }^{3} \mathrm{~F}_{4}$ takes place ET from the $\mathrm{Yb}^{3+}$ (step 2) that causes the ${ }^{3} \mathrm{~F}_{4} \rightarrow{ }^{3} \mathrm{~F}_{2,3}$ transition of $\mathrm{Tm}^{3+}$. From this energy level the $\mathrm{Tm}^{3+}$ ions can firstly nonradiatively relax to ${ }^{3} \mathrm{H}_{4}$ and then radiatively relax to the ground state $\left({ }^{3} \mathrm{H}_{6}\right)$. The latter transition generates the NIR emission band centered at $826 \mathrm{~nm}\left(11990 \mathrm{~cm}^{-1}\right)$ in the spectra shown in Fig. 1B. Step (3) allows to excite $\mathrm{Tm}^{3+}$ to the ${ }^{1} \mathrm{G}_{4}$ state. From this level start three emission transitions of $\mathrm{Tm}^{3+}$, viz. ${ }^{1} \mathrm{G}_{4} \rightarrow{ }^{3} \mathrm{H}_{5},{ }^{1} \mathrm{G}_{4} \rightarrow{ }^{3} \mathrm{~F}_{4}$ and ${ }^{1} \mathrm{G}_{4} \rightarrow{ }^{3} \mathrm{H}_{6}$ which correspond to bands at $810 \mathrm{~nm}\left(12250 \mathrm{~cm}^{-1}\right), 637 \mathrm{~nm}\left(15635 \mathrm{~cm}^{-1}\right)$ and $484 \mathrm{~nm}$ $\left(20640 \mathrm{~cm}^{-1}\right.$ ), respectively. After the next ESA (step 4) the $\mathrm{Tm}^{3+}$ ions are transferred to the ${ }^{1} \mathrm{D}_{2}$ state from which they can relax by photon emissions of wavelengths of $792 \mathrm{~nm}\left(12540 \mathrm{~cm}^{-1}\right)$ and $470 \mathrm{~nm}\left(21220 \mathrm{~cm}^{-1}\right)$. In this case the emission lines are related to ${ }^{1} \mathrm{D}_{2} \rightarrow{ }^{3} \mathrm{~F}_{2,3}$ and ${ }^{1} \mathrm{D}_{2} \rightarrow{ }^{3} \mathrm{~F}_{4}$ transitions, respectively. ${ }^{22}$

The up-conversion mechanism in the triply co-doped nanocrystals and nanocomposite could be more complicated because such pairs of energy levels as $\left(\mathrm{Ho}^{3+}:{ }^{5} \mathrm{I}_{7}\right.$ and $\left.\mathrm{Tm}^{3+}:{ }^{3} \mathrm{~F}_{4}\right)$, $\mathrm{Ho}^{3+}:{ }^{5} \mathrm{I}_{6}$ and $\mathrm{Tm}^{3+}:{ }^{3} \mathrm{H}_{5}, \mathrm{Ho}^{3+}:{ }^{5} \mathrm{~F}_{5}$ and $\mathrm{Tm}^{3+}:{ }^{3} \mathrm{~F}_{2,3}$ as well as $\mathrm{Ho}^{3+}:{ }^{5} \mathrm{~F}_{1}$ and $\mathrm{Tm}^{3+}::^{1} \mathrm{G}_{4}$ possessing small energy differences between them (compare in Fig. 2). Thus, a quasi-resonant ET $\mathrm{Ho}^{3+} \rightarrow \mathrm{Tm}^{3+}$, e.g. $\mathrm{Ho}^{3+}:{ }^{5} \mathrm{~F}_{5} \rightarrow \mathrm{Tm}^{3+}:{ }^{3} \mathrm{~F}_{2,3}$ and next multiphonon non-radiative transitions (NRTs) to the $\mathrm{Ho}^{3+}:{ }^{5} \mathrm{I}_{7}$ and $\mathrm{Tm}^{3+}:{ }^{3} \mathrm{H}_{4}$ : levels could be taken into account (see right part of the diagram in Fig. 2). In this case population of the $\mathrm{Tm}^{3+}:^{1} \mathrm{G}_{4}$ state can be reached in the three-photon processes as follows: $\mathrm{Yb}^{3+}:{ }^{2} \mathrm{~F}_{7 / 2} \rightarrow \mathrm{GSA} \mathrm{Yb}^{3+}:{ }^{2} \mathrm{~F}_{5 / 2} \rightarrow \mathrm{ESA} \mathrm{Ho}^{3+}:{ }^{5} \mathrm{I}_{6} \rightarrow \mathrm{NRT} \mathrm{Ho}^{3+}:{ }^{5} \mathrm{I}_{7} \rightarrow$ ESA $\mathrm{Ho}^{3+}: \mathrm{F}_{5} \rightarrow$ ET $\mathrm{Tm}^{3+}:{ }^{3} \mathrm{~F}_{2,3} \rightarrow$ NRT $\mathrm{Tm}^{3+}:{ }^{3} \mathrm{H}_{4} \rightarrow$ ESA $\mathrm{Tm}^{3+}:{ }^{1} \mathrm{G}_{4}$. The other observed bands are assigned to the same $\mathrm{Ho}^{3+}$ electronic transitions as in the doubly co-doped samples

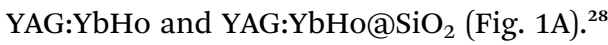

The material consisting of the triply co-doped YAG nanocrystals (YAG:YbTmHo) embedded into silica (YAG:YbTmHo@SiO ${ }_{2}$ ) was excited under $355 \mathrm{~nm}$, i.e. the excitation wavelength typical for $\mathrm{Tm}^{3+}, \mathrm{Ho}^{3+}$ ions and additionally for silica matrix (see Fig. 3). The appropriate emission spectra of the YAG:YbTmHo@SiO $\mathrm{S}_{2}$ phosphor dried at $200{ }^{\circ} \mathrm{C}$ and then calcined at 600,800 and $1000{ }^{\circ} \mathrm{C}$ are demonstrated in Fig. 3 . Characteristic feature of the spectra is a band wing penetrated deeply from UV into the visible range. This wing is the long wavelength part of the spectrum (Fig. 3, inset) attributed to 


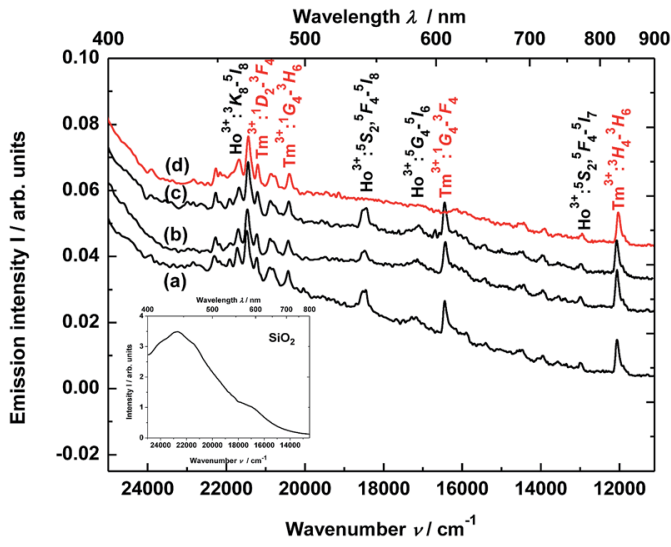

Fig. 3 Steady-state emission spectra of the YAG:YbTmHo@SiO nanocomposite excited under $355 \mathrm{~nm}$ after drying at (a) $200{ }^{\circ} \mathrm{C}$ and calcined at: (b) 600 , (c) 800 and (d) $1000{ }^{\circ} \mathrm{C}$ for $3 \mathrm{~h}$. Inset presents emission spectrum of $\mathrm{SiO}_{2}$ xerogel dried at $200{ }^{\circ} \mathrm{C}$ and excited under $355 \mathrm{~nm}$.

electronic transitions between structural defect levels of amorphous $\mathrm{SiO}_{2}{ }^{29,30}$ Emission lines of $\mathrm{Tm}^{3+}$ and $\mathrm{Ho}^{3+}$ are observed against the wing background. The distinct $\mathrm{Ho}^{3+}$ bands attributed to ${ }^{5} \mathrm{~S}_{2},{ }^{5} \mathrm{~F}_{4} \rightarrow{ }^{5} \mathrm{I}_{8}$ (peaked at $541 \mathrm{~nm}, 18484 \mathrm{~cm}^{-1}$ ) and ${ }^{5} \mathrm{G}_{4} \rightarrow{ }^{5} \mathrm{I}_{6}$ (at $585 \mathrm{~nm}, 17094 \mathrm{~cm}^{-1}$ ) transitions are present only in the spectra of the material thermally treated in the $200-800^{\circ} \mathrm{C}$ range (curves a-c). While the $\mathrm{Ho}^{3+}$ bands centered at $466 \mathrm{~nm}$ $\left(21459 \mathrm{~cm}^{-1}\right)$ and $771 \mathrm{~nm}\left(12970 \mathrm{~cm}^{-1}\right)$ ascribed to ${ }^{3} \mathrm{~K}_{8} \rightarrow{ }^{5} \mathrm{I}_{8}$ and ${ }^{5} \mathrm{~S}_{2},{ }^{5} \mathrm{~F}_{4} \rightarrow{ }^{5} \mathrm{I}_{7}$ transitions, respectively, are present also after calcination at $1000{ }^{\circ} \mathrm{C}$ (curve d). The $\mathrm{Tm}^{3+}$ bands corresponding to ${ }^{1} \mathrm{D}_{2} \rightarrow{ }^{3} \mathrm{~F}_{4}$ (466 nm, $21459 \mathrm{~cm}^{-1}$ ), ${ }^{1} \mathrm{G}_{4} \rightarrow{ }^{3} \mathrm{H}_{6}$ (491, 20367 ), ${ }^{1} \mathrm{G}_{4} \rightarrow{ }^{3} \mathrm{~F}_{4}(608,16447)$ and ${ }^{3} \mathrm{H}_{4} \rightarrow{ }^{3} \mathrm{H}_{6}(832,12019)$ transitions are also present in all the spectra (a-d). One can assume that the faint red emission related to the ${ }^{5} \mathrm{~S}_{2},{ }^{5} \mathrm{~F}_{4} \rightarrow{ }^{5} \mathrm{I}_{7}$ transition of $\mathrm{Ho}^{3+}$ is present by additional population for the $\left({ }^{5} \mathrm{~S}_{2},{ }^{5} \mathrm{~F}_{4}\right)$ levels by energy transfer from $\mathrm{Tm}^{3+}$ to $\mathrm{Ho}^{3+}$ ions. ${ }^{31}$ However, the $\mathrm{Ho}^{3+}$ band quenching in range between 530 and $600 \mathrm{~nm}$ signifies that the $\mathrm{Tm}^{3+} \rightarrow \mathrm{Ho}^{3+}$ energy transfer in the material thermally treated at $1000{ }^{\circ} \mathrm{C}$ did not exist in this case. ${ }^{32,33}$ The set of the emission spectra in Fig. 3 suggests that $600{ }^{\circ} \mathrm{C}$ as the lowest calcination temperature applied for $3 \mathrm{~h}$ allows to obtain optimal luminescence properties of the nanocomposite material.

Thus, the luminescence excitation spectrum of the YAG:YbTmHo@SiO ${ }_{2}$ nanocomposite calcined at $600{ }^{\circ} \mathrm{C}$ for $3 \mathrm{~h}$ is demonstrated in Fig. 4. The spectrum monitored at $466 \mathrm{~nm}$ (corresponding to $\mathrm{Tm}^{3+}:{ }^{1} \mathrm{D}_{2} \rightarrow{ }^{3} \mathrm{~F}_{4}$ and $\mathrm{Ho}^{3+}:{ }^{3} \mathrm{~K}_{8} \rightarrow{ }^{5} \mathrm{I}_{8}$ transitions as well as simultaneously transition in the amorphous silica) consists of lines centered at: $284 \mathrm{~nm}\left(35211 \mathrm{~cm}^{-1}\right.$, corresponding to transitions $\mathrm{Ho}^{3+}: \mathrm{I}_{8} \rightarrow{ }^{3} \mathrm{G}_{3},{ }^{3} \mathrm{~L}_{8}$ and $\mathrm{Tm}^{3+}:{ }^{3} \mathrm{H}_{6} \rightarrow{ }^{3} \mathrm{P}_{0}$ ), 290 (34 483, Ho ${ }^{3+}:{ }^{5} \mathrm{I}_{8} \rightarrow{ }^{3} \mathrm{D}_{3}$ ), $319\left(31348, \mathrm{Ho}^{3+}:{ }^{5} \mathrm{I}_{8} \rightarrow{ }^{5} \mathrm{G}_{2}\right.$ ), $343\left(29155, \mathrm{Ho}^{3+}: \mathrm{I}_{8} \rightarrow{ }^{5} \mathrm{G}_{3}\right), 355\left(28169, \mathrm{Ho}^{3+}::^{5} \mathrm{I}_{8} \rightarrow{ }^{3} \mathrm{H}_{6}\right.$ and $\left.\mathrm{Tm}^{3+}:{ }^{3} \mathrm{H}_{6} \rightarrow{ }^{1} \mathrm{D}_{2}\right), 384\left(26042, \mathrm{Ho}^{3+}:{ }^{5} \mathrm{I}_{8} \rightarrow{ }^{5} \mathrm{G}_{4}\right), 399(25063$, $\left.\mathrm{Ho}^{3+}::^{5} \mathrm{I}_{8} \rightarrow{ }^{3} \mathrm{~K}_{7}\right), 415\left(24096, \mathrm{Ho}^{3+}: \mathrm{I}_{8} \rightarrow{ }^{5} \mathrm{G}_{5}\right), 425$ (23 529, $\left.\mathrm{Ho}^{3+}:{ }^{5} \mathrm{I}_{8} \rightarrow{ }^{5} \mathrm{G}_{6}\right)$ and $435\left(22989, \mathrm{Ho}^{3+}:{ }^{5} \mathrm{I}_{8} \rightarrow{ }^{5} \mathrm{~F}_{1}\right)$. In the inset is presented excitation spectrum of glassy $\mathrm{SiO}_{2}$. This spectrum is attributed to many transitions between defects states in the amorphous silica matrix.

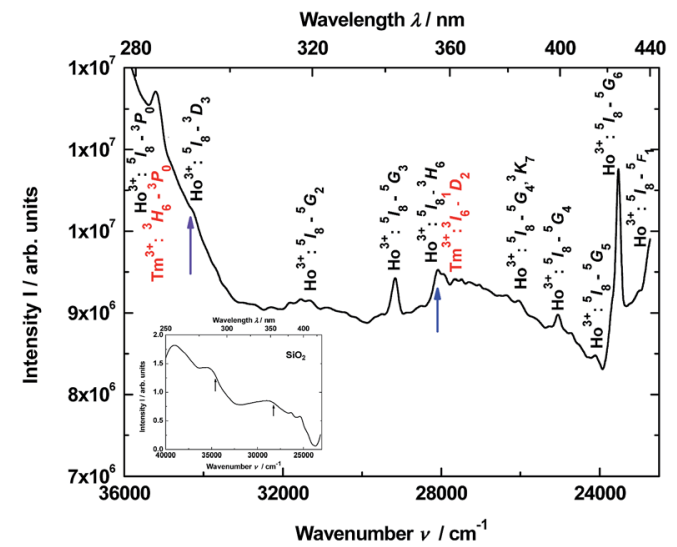

Fig. 4 Excitation spectrum of the YAG:YbTmHoaSiO 2 nanocomposite monitored at $466 \mathrm{~nm}$. The nanocomposite was calcined at $600{ }^{\circ} \mathrm{C}$ for $3 \mathrm{~h}$. The inset demonstrates excitation spectrum of pure $\mathrm{SiO}_{2}$ glass monitored at $440 \mathrm{~nm}$. The arrows indicate the excitation wavelengths (290 and $355 \mathrm{~nm}$ ) used in steady-state condition.

\section{Time-resolved luminescence}

To obtain time-resolved spectra, the YAG:YbTmHo@SiO ${ }_{2}$ nanocomposite was excited using of a YAG:Nd laser and system OPG (see Apparatus). The apparatus allows to integrate luminescence in the $0-200 \mu$ s time interval. The spectra are collected in Fig. 5. Obviously, they are superpositions consisting of $\mathrm{Tm}^{3+}$ and $\mathrm{Ho}^{3+}$ bands. When the sample is excited under $290 \mathrm{~nm}$ (see curve a), among the lines there are four most intensive bands, viz. the resultant emission band peaked at $371 \mathrm{~nm}$ (26 $963 \mathrm{~cm}^{-1}$ ) attributed to $\mathrm{Tm}^{3+}:{ }^{1} \mathrm{D}_{2} \rightarrow{ }^{3} \mathrm{H}_{6}$ and $\mathrm{Ho}^{3+}:{ }^{3} \mathrm{H}_{6} \rightarrow{ }^{5} \mathrm{I}_{8}$ transitions. The next band placed at $466 \mathrm{~nm}\left(21459 \mathrm{~cm}^{-1}\right)$ is a result of overlapping three bands related to both transitions of $\mathrm{Tm}^{3+}:{ }^{1} \mathrm{D}_{2} \rightarrow{ }^{3} \mathrm{~F}_{4}$ and ${ }^{1} \mathrm{G}_{4} \rightarrow{ }^{3} \mathrm{H}_{6}$ as well as the $\mathrm{Ho}^{3+}:{ }^{3} \mathrm{~K}_{8} \rightarrow{ }^{5} \mathrm{I}_{8}$ transition. Whereas lines centered at $652\left(15337 \mathrm{~cm}^{-1}\right)$ and $736 \mathrm{~nm}\left(13592 \mathrm{~cm}^{-1}\right)$ are owing to the ${ }^{1} \mathrm{G}_{4} \rightarrow{ }^{3} \mathrm{~F}_{4}$ transition of $\mathrm{Tm}^{3+}$ and the ${ }^{5} \mathrm{~S}_{2},{ }^{5} \mathrm{~F}_{4} \rightarrow{ }^{5} \mathrm{I}_{7}$ transitions of $\mathrm{Ho}^{3+}$, respectively.

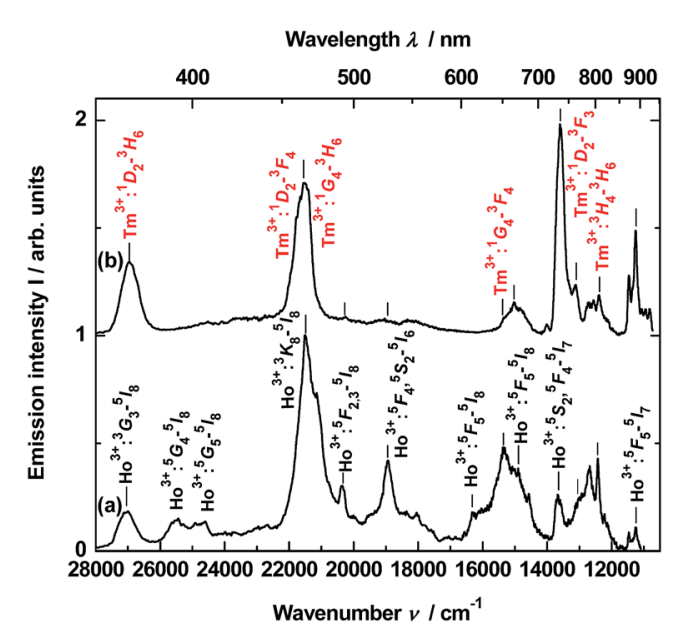

Fig. 5 Time-resolved emission spectra of the YAG:YbTmHoaSiO calcined at $600^{\circ} \mathrm{C}$ for $3 \mathrm{~h}$. The material was excited by the pulse laser under: (a) 290 and (b) $355 \mathrm{~nm}$ and the luminescence was integrated for the time interval $0-200 \mu \mathrm{s}$. 
Similar bands or their traces are present in the emission spectrum excited under $355 \mathrm{~nm}$ (see Fig. 5, curve b). However, mutual intensity ratios of the bands are quite other and two lines centered at $393(25434)$ and 407 (24 593) as well as a shoulder at ca. $615 \mathrm{~nm}\left(16345 \mathrm{~cm}^{-1}\right)$ are absent in comparison to the spectrum excited under $290 \mathrm{~nm}$ (curve a). Moreover, the spectrum (curve b) differs from the emission spectrum excited under the same wavelength but in steady-state condition (see Fig. 3, curve b).

Photoluminescence lifetime measurements for YAG:YbTmHo@SiO $\mathrm{Si}_{2}$ were performed by the pulsed laser under excitation at $290 \mathrm{~nm}$ (see decay curves in Fig. 6). The average lifetime values for electronic transitions related to the four most intense lines mentioned above (see Fig. 5) are presented in Table 1 . The average decay times $\tau_{\mathrm{av}}$ were evaluated using the equation: ${ }^{34}$

$$
\tau_{\mathrm{av}}=\frac{\int t I(t) \mathrm{d} t}{\int I(t) \mathrm{d} t}
$$

where $I(t)$ is the emission intensity at time $t$.

Calculated average decay times $\tau_{\mathrm{av}}$ of the above mentioned transitions are listed in Table 1 for $\lambda_{\text {exc }}=290$ and $355 \mathrm{~nm}$. One notes that independently on the excitation wavelength the decay times demonstrate approximate values for the observed transitions in both lanthanide dopants of YAG nanoparticles incorporated into silica matrix.

In much shorter time interval (0-50 ns) and under $290 \mathrm{~nm}$ excitation was observed for the YAG:Yb,TmHo@SiO ${ }_{2}$ only a time-resolved spectrum of the vitreous silica matrix (Fig. 7). The spectrum consists of a strong and broad emission band centered at ca. $440 \mathrm{~nm}\left(22738 \mathrm{~cm}^{-1}\right)$. Its origin is attributed to photon recombinations from numerous defects (as dangling bonds) in the amorphous silica. ${ }^{29,30}$

The measured decay profile of the silica luminescence under excitation by the pulse laser at $290 \mathrm{~nm}$ is shown in Fig. 8. The curve allows to estimate average emission decay time value for silica equal to $5.6 \pm 0.6 \mathrm{~ns}$.

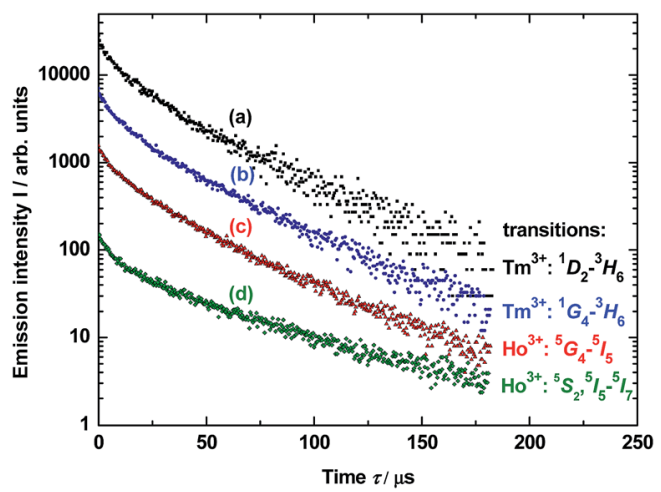

Fig. 6 Decay luminescence curves for electronic transitions related to four emission lines of $\mathrm{Tm}^{3+}$ and $\mathrm{Ho}^{3+}$ dopants in YAG nanocrystals incorporated into $\mathrm{SiO}_{2}$ matrix (YAG:YbTmHo@SiO 2 ) calcined at $600{ }^{\circ} \mathrm{C}$ for $3 \mathrm{~h}$ and excited under $290 \mathrm{~nm}$. The lines are presented in the spectra in Fig. 3 (curve b). For details vide supra.
Table 1 Selected electronic transitions of the co-doping $\mathrm{Tm}^{3+}$ and $\mathrm{Ho}^{3+}$ ions in YAG nanocrystals entrapped in silica matrix (YAG:YbTmHo@SiO ${ }_{2}$ ) and their average decay times

\begin{tabular}{llll}
\hline & & \multicolumn{2}{l}{ Average decay time $\tau_{\text {av }} / \mu \mathrm{s}$} \\
\cline { 3 - 3 } & & $\begin{array}{l}\text { Excitation wavelength } \\
\lambda_{\text {exc }} / \mathrm{nm}\end{array}$ \\
\hline $\mathrm{Ln}^{3+}$ & Transition & 290 & 355 \\
\hline $\mathrm{Tm}^{3+}$ & ${ }^{1} \mathrm{D}_{2} \rightarrow{ }^{3} \mathrm{H}_{6}$ & $41 \pm 3$ & $30 \pm 2$ \\
$\mathrm{Tm}^{3+}$ & ${ }^{1} \mathrm{G}_{4} \rightarrow{ }^{3} \mathrm{H}_{6}$ & $36 \pm 3$ & $28 \pm 2$ \\
$\mathrm{Ho}^{3+}$ & ${ }^{5} \mathrm{G}_{4} \rightarrow{ }^{5} \mathrm{I}_{5}$ & $33 \pm 2$ & $36 \pm 3$ \\
$\mathrm{Ho}^{3+}$ & ${ }^{5} \mathrm{~S}_{2},{ }^{5} \mathrm{~F}_{4} \rightarrow{ }^{5} \mathrm{I}_{7}$ & $30 \pm 2$ & $41 \pm 3$
\end{tabular}

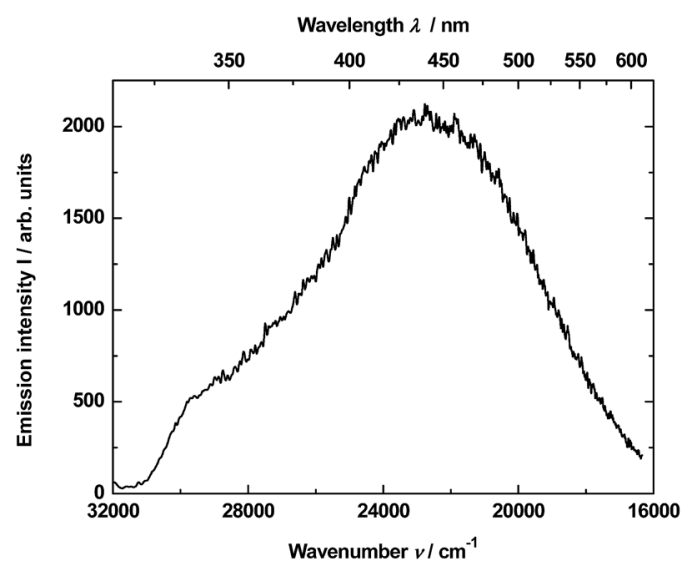

Fig. 7 Time-resolved emission spectrum of the YAG:YbTmHo@SiO nano-composite calcined at $600{ }^{\circ} \mathrm{C}$ for $3 \mathrm{~h}$ and excited at $290 \mathrm{~nm}$ by the pulse laser. The luminescence was integrated in the time interval $0-50 \mathrm{~ns}$.

\section{Chromaticity}

The emission spectra of the YAG:YbTmHo@SiO ${ }_{2}$ glassnanocomposite under different excitation wavelengths and luminescence techniques (such as the steady state and pulse laser measurements) are demonstrated in Fig. 9. Under the $355 \mathrm{~nm}$ excitation (curve a) in the steady-state condition, the nanocomposite material emits simultaneously reddish, green

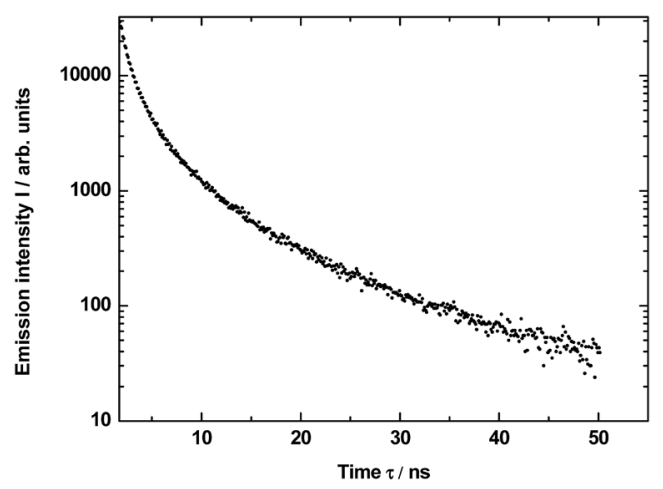

Fig. 8 Decay of the luminescence excited under $290 \mathrm{~nm}$ and integrated in the band $450-470 \mathrm{~nm}$ for $\mathrm{SiO}_{2}$ matrix in YAG:YbTmHoaSiO material calcined at $600^{\circ} \mathrm{C}$ for $3 \mathrm{~h}$. Average lifetime $\tau_{\mathrm{av}}=5.6 \pm 0.6 \mathrm{~ns}$. 


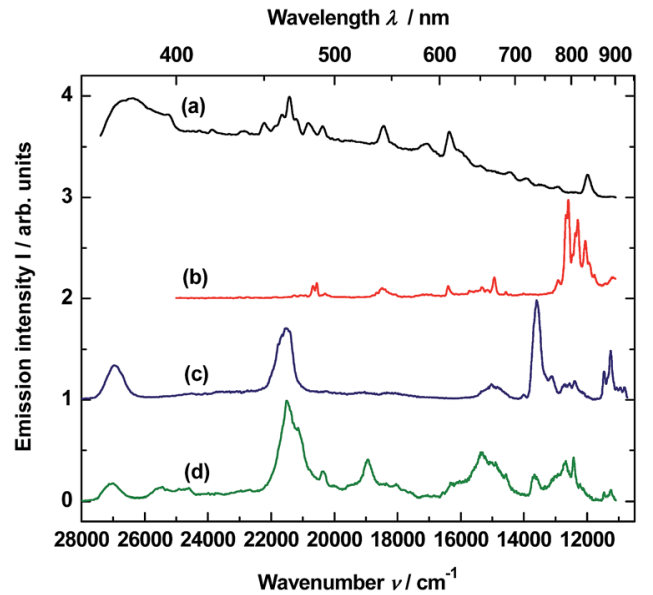

Fig. 9 Comparison of the steady-state emission spectra excited under: (a) $355 \mathrm{~nm}$ and (b) $980 \mathrm{~nm}$ (up-conversion) as well as excited by the pulse laser under: 355 (c) and $290 \mathrm{~nm}$ (d) for the YAG:YbTmHoaSiO 2 nanocomposite calcined at $600{ }^{\circ} \mathrm{C}$ for $3 \mathrm{~h}$. The luminescence in the cases (c) and (d) was integrated in the time interval $0-200 \mu \mathrm{s}$.

and blue (RGB) luminescent light (see Fig. 3 curve b). ${ }^{35}$ The emissions are ascribed to the transitions of $\mathrm{Tm}^{3+}$ and $\mathrm{Ho}^{3+}$ ions, while blue emission is especially intense due to electronic transition in silica (see Fig. 3, inset). The up-conversion spectrum (curve b) obtained under $980 \mathrm{~nm}$ excitation by the laser in steady-state condition supply with red, green and bluish green light owing to the transitions of $\mathrm{Tm}^{3+}$ and $\mathrm{Ho}^{3+}$ ions (compare Fig. 1B). On the other hand, under excitations 355 and $290 \mathrm{~nm}$ by the pulse laser (curves $\mathrm{c}$ and $\mathrm{d}$, respectively) also the both lanthanide ions are responsible for the emission in visible range. However, the $355 \mathrm{~nm}$ excitations delivers only red and blue emission (Fig. 5, curve b), while under $290 \mathrm{~nm}$ excitation is observed light consisting of emissions of primary colours (RGB) (Fig. 5, curve a).

The CIE chromaticity coordinates and diagram of YAG:YbTmHo@SiO ${ }_{2}$ under the different excitation wavelengths and luminescent techniques are presented in Table 2 and Fig. 10, respectively. The luminescent nanocomposite emits cold white light with bluish tone (point A), when excited by $355 \mathrm{~nm}$ in steady state-condition. In this case the correlated colour temperature $\left(T_{\mathrm{cc}}\right)$ is rather high $(\mathrm{ca} .8100 \mathrm{~K}) .{ }^{36}$ Whereas the up-conversion emission (point B) excited at $980 \mathrm{~nm}$ in the same condition is white and its $T_{\mathrm{cc}} \approx 4800 \mathrm{~K}$ is in between temperatures of mean noon sunlight and household tungsten-

Table 2 The $\mathrm{CIE}$ coordinates of the $\mathrm{YAG}: \mathrm{YbTmHo} \mathrm{CSiO}_{2}$ glassnanocomposite calcined at $600{ }^{\circ} \mathrm{C}$ for $3 \mathrm{~h}$

\begin{tabular}{lllll}
\hline Sample & $X$ & $Y$ & $T_{\text {cc }} \mathrm{K}$ & $\lambda_{\text {exc }} \mathrm{nm}$ \\
\hline A & 0.300 & 0.307 & 8100 & 355 \\
B & 0.359 & 0.351 & 4800 & 980 \\
C & 0.194 & 0.191 & $-{ }^{a}$ & $355^{b}$ \\
D & 0.260 & 0.282 & 14000 & $290^{b}$
\end{tabular}

${ }^{a}$ Impossible to evaluate due to high $T_{\text {cc. }}{ }^{b}$ Excited by the pulse laser.

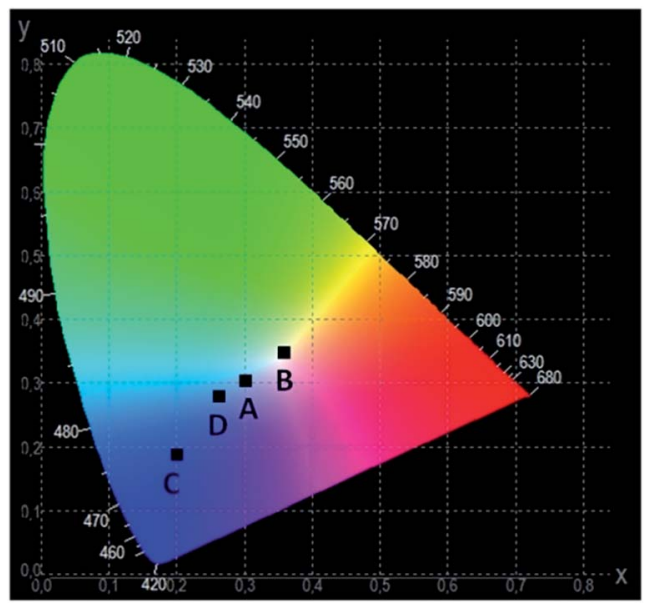

Fig. 10 The $\mathrm{ClE}$ chromaticity diagram of the YAG:YbTmHo@SiO 2 nanocomposite calcined at $600{ }^{\circ} \mathrm{C}$ for $3 \mathrm{~h}$. For details see Table 2 .

filament light bulb $(100 \mathrm{~W}){ }^{35,36}$ Both the emissions excited under 290 and $355 \mathrm{~nm}$ by pulse laser emitted blue light which $T_{\text {cc }}$ values in the former case (point D) is equal to $14000 \mathrm{~K}$ but in the latter case (point C) $T_{\mathrm{cc}}$ is too high to evaluate them.

\section{Conclusions}

The glass nanocomposite, i.e. nanocrystalline YAG co-doped with $\mathrm{Yb}^{3+}, \mathrm{Tm}^{3+}$ and $\mathrm{Ho}^{3+}$ entrapped in glassy silica (YAG:YbTmHo@SiO ${ }_{2}$ ), was successively prepared by sol-gel method. Presence of the specific lanthanide ions such as $\mathrm{Yb}^{3+}$, $\mathrm{Tm}^{3+}$ and $\mathrm{Ho}^{3+}$ in the nanocomposite allows to observe upconversion effect, when the composite sample was excited under $980 \mathrm{~nm}$ in steady-state condition. Other steady-state emission was also recorded, when $\lambda_{\text {exc }}=355 \mathrm{~nm}$. The nanocomposite material excited by pulse laser shows dissimilar time-resolved luminescence spectra for different excitation wavelengths $\left(\lambda_{\text {exc }}=290\right.$ and $\left.355 \mathrm{~nm}\right)$. Luminescence property based on up-conversion effect of the glass-nanocomposite excited under $980 \mathrm{~nm}$ in steady-state condition allows to recognize the material as a white phosphor candidate.

\section{Conflicts of interest}

There are no conflicts to declare.

\section{Acknowledgements}

We would like to express our gratitude to Prof. Dr Marek Grinberg (Institute of Experimental Physics, University of Gdańsk, Poland) and Prof. Dr Wiesław Wiczk (Faculty of Chemistry, University of Gdańsk, Poland) for making the apparatus accessible for the measurements. K. S. has been supported by the National Centre for Research and Development by grant NOPLID PL-TWII/8/2015. 


\section{References}

1 J. Xu, M. Sun, Y. Kuang, H. Bi, B. Liu, D. Yang, R. Lv, S. Gai, F. He and P. Yang, Dalton Trans., 2017, 46, 1495-1501.

2 J. Jin, K. Yang, J. Su and Z. Si, J. Lumin., 2015, 159, 178-182.

3 G. Blasse and B. C. Grabmaier, Luminescent Materials, Springer-Verlag, Berlin, 1994, ch. 10.

4 C. S. Lim, V. V. Atuchin, A. S. Aleksandrovsky, M. S. Molokeev and A. S. Oreshonkov, J. Alloys Compd., 2017, 695, 737-746.

5 H. W. Zheng, S. J. Liu, G. S. Yin, W. C. Wang, C. L. Diao, Y. Z. Gu and W. F. Zhang, J. Sol-Gel Sci. Technol., 2011, 59, 290-296.

6 X. Mateos, M. C. Pujol, F. Güell, R. Sole, J. Gavalda, J. Massons, M. Aguilo and F. Diaz, Opt. Mater., 2004, 27, 475-479.

7 M. Nakielska, J. Sarnecki, M. Malinowski and R. Piramidowicz, J. Alloys Compd., 2008, 451, 190-193.

8 J. Zhang and J. Jia, J. Lumin., 2016, 174, 1-5.

9 F. G. Yang, F. P. Yan, Z. Y. You, C. Y. Tu, C. L. Sun, Y. Wang, Z. J. Zhu and J. F. Li, Laser Phys. Lett., 2010, 7, 867-869.

10 L. Marciniak, A. Bednarkiewicz and W. Stręk, J. Lumin., 2017, 184, 179-184.

11 S. Hu, J. Yang, C. Li and J. Lin, Mater. Chem. Phys., 2012, 133, 751-756.

12 A. Ikesue, T. Kinoshita, K. Kamata and K. Yoshida, J. Am. Chem. Soc., 1995, 78, 1033-1040.

13 S. Pfeifer, M. Bischoff, R. Niewa, B. Clauss and M. R. Buchmeister, J. Eur. Ceram. Soc., 2014, 34, 1321-1328.

14 X.-X. Ge, Y.-H. Sun, C. Liu and W.-K. Qi, J. Sol-Gel Sci. Technol., 2009, 52, 179-187.

15 R. Muenchausen, L. G. Jacobsohn, B. L. Bennett, E. A. McKigney, J. F. Smith, J. A. Valdez and D. W. Cooke, J. Lumin., 2007, 126, 838-842.

16 B. Karmakar, Fundamentals of Glass and Glass Nanocomposites in Glass Nanocomposites, Synthesis, Properties and Applications, ed. B. Karmakar, K. Rademann, A. L. Stepanov, Elsevier, Amsterdam, 2016.

17 C. J. Brinker and G. W. Scherer, Sol-Gel Science: The Physics and Chemistry of Sol-Gel Processing, Academic Press, Boston, 1990.

18 J. Zhao, X. Zheng, E. P. Schartner, P. Ionescu, R. Zhang, T.-L. Nguyen, D. Jin and H. Ebendorff-Heidepriem, Adv. Opt. Mater., 2016, 4, 1507-1517.
19 J. Zhao, D. Jin, E. P. Schartner, Y. Lu, Y. Liu, A. V. Zvyagin, L. Zhang, J. M. Dawes, P. Xi, J. A. Piper, E. M. Goldys and T. M. Monro, Nat. Nanotechnol., 2013, 8, 729-734.

20 D. J. Gargas, E. M. Chan, A. D. Ostrowski, S. Aloni, M. V. P. Altoe, E. S. Barnard, B. Sanii, J. J. Urban, D. J. Milliron, B. E. Cohen and P. J. Schuck, Nat. Nanotechnol., 2014, 9, 300-305.

21 D. Liu, X. Xu, Y. Du, X. Qin, Y. Zhang, C. Ma, S. Wen, W. Ren, E. M. Goldys, J. Pieper, S. Dou, X. Liu and D. Jin, Nat. Commun., 2016, 7, 10432-10438.

22 J. Zhou, G. Chen, Y. Zhu, L. Huo, W. Mao, D. Zou, X. Sun, E. Wu, H. Zeng and J. Zhang, J. Mater. Chem. C, 2015, 3, 364-369.

23 J. Wang, R. Deng, M. A. MacDonald, B. Chen, J. Yuan, F. Wang, D. Chi, T. S. Andy Hor, P. Zhang, G. Liu, Y. Han and X. Liu, Nat. Mater., 2014, 13, 157-162.

24 M. Veith, S. Mathur, A. Kareiva, M. Jilavi, M. Zimmer and V. Huch, J. Mater. Chem., 1999, 9, 3069-3079.

25 M. Kubus, H.-J. Meyer, L. Kienle and A. M. Kłonkowski, J. Non-Cryst. Solids, 2009, 355, 1333-1337.

26 D. Pawlak, K. Wozniak, Z. Frukacz, T. L. Barr, D. Fiorentino and S. Seal, J. Phys. Chem. B, 1999, 103, 1454-1461.

27 A. Kubicki, P. Bojarski, M. Grinberg, M. Sadownik and B. Kukliński, Opt. Commun., 2006, 263, 275-280.

28 J. Żmojda, D. Dorosz, M. Kochanowicz, P. Miluski and J. Dorosz, Acta Phys. Pol., A, 2013, 124, 598-601.

29 L. N. Skuja, J. Non-Cryst. Solids, 1992, 149, 77-95.

30 A. M. Kłonkowski, W. Wiczk, J. Ryl, K. Szczodrowski and D. Wileńska, J. Alloys Compd., 2017, 724, 649-658.

31 A. C. Yanes, J. J. Velazquez, J. del-Castillo, J. Mendez-Ramos and V. D. Rodriguez, J. Sol-Gel Sci. Technol., 2009, 51, 4-9.

32 D. Wang, Y. Guo, G. Sun, J. Li, L. Zhao and G. Xu, J. Alloys Compd., 2008, 451, 122-124.

33 D. Chen, Y. Wang, Y. Yu, P. Huang and F. Weng, J. Solid State Chem., 2008, 181, 2763-2769.

34 S. Shinoya and W. M. Yen, Phosphor Handbook, CRC Press, Boca Raton, 1999.

35 R. J. D. Tilley, Colour and the optical properties of materials, J. Wiley, Chichester, 2 edn, 2011, ch 3.

36 http://www.vendian.org/mncharity/dir3/blackbody/Unstable URLs/bbr_color.html. 